\title{
An Investigation on the Use of English From the Perspective of Graduates Majored in Economics and Business
}

\author{
Shuhua Wanger ${ }^{1, \text { a }}$ \\ ${ }^{1}$ School of Foreign Languages and Cultures, Beijing Wuzi University, Beijing, 101149, China \\ aemail: wangshuhua@bwu.edu.cn
}

Keywords: Needs Analysis; Use of English; Workplace; Investigation

\begin{abstract}
English is a compulsory course for college non-English majors, and a key to an ideal post in job-hunting as well when the globalization of economy attaches much importance to it. To train their graduates to have an international perspective and to meet social needs, colleges need to carry out curriculum reforms based on the knowledge of English using in workplaces. This research investigates the social needs of English from the perspective of graduates who majored in Economics and Business so as to provide practical suggestions for both the reform of College English Teaching and college students’ learning English as a preparation for their future job.
\end{abstract}

\section{Introduction}

English has become a global language and been widely used worldwide. Nearly 400 million people are native English speakers; almost one out of ten people use English as their mother language. As China deepened reform and opening up as well as joined WTO, the need of communication with the world has become increasingly important. English is not only a compulsory course for non-English majors, but also a key qualification in their job-hunting. It to some extent symbolizes the level of education [1].

Many colleges have carried out curriculum reforms in terms of students' learning method and process in order to meet the needs of social developments based on teachers' belief [2, 3], but these reforms seldom took the learners views into consideration. In fact such questions related to learners' needs should be answered before reforms are done: Do college graduates think that English is important in their job hunting and workplaces? How often do college graduates use English in the working field? What is the typical occasion of using English? What is the most important part in English communication? etc. As to graduates have diverse needs in English learning, which is decided by their major and what kind of job they'd like to do, this essay, taking the students major in economics and business as subjects, is trying to find out the answers to the above questions. Afterwards, the author would put forward some practical suggestions towards college English teaching and learning so as to make them productive and help graduates better prepared for their future job.

\section{Needs Analysis and Relevant Researches}

Needs analysis has been applied in foreign language teaching research for two or three decades. It was originally used in Language for specific purpose research [4]. We can use needs analysis to identify some problems in the instruction and students' learning and to improve the teaching and learning in the process of TEFL [5]. "Need" can be defined as a necessity for those who want to master a foreign language. The ignoring of the learner's need lead to the low achievement in English teaching. Furthermore, we can regard need as deficiency, which is the thing that cannot be obtained by learners during the process of English learning. Needs analysis is meaningful because if students have a comprehensive understanding of their present study and future work, they can easily achieve study requirements and better control the use of language [6]. The ultimate goal of needs analysis is to help improve teaching with empirical evidence instead of using some subjective judgments. 
Several researchers conducted surveys on the use of English and Long's research is a typical one [7]. He surveyed non-English major graduates in Beijing normal university and found that: 1) More than $60 \%$ of the graduates believe it is the comprehensive English ability that work for their future development, but the frequency of English using is generally not high. 2) Among the English language ability, the hardest top three in turn is: writing, speaking and listening. 3) In terms of curriculum, more than $80 \%$ of them think that college English education should focus on cultivating the comprehensive use of English, especially speaking and listening.

Long's research did not cover the fields that graduates work in nor the specific occasions that that they use English to deal with. The author of this paper tends to do a more detailed investigation, not only on the importance of English and the specific language skills, but also to find out their positions in the workplace and the specific occasions of using English. In addition, graduates' opinions of our university's English teaching will be asked so that they can give proper suggestions on the improvement of teaching.

\section{Methodology}

\section{Research questions}

A questionnaire survey is conducted to answer the following research questions:

1. What are the graduates' main job responsibilities?

2. Which is the essential language skill for workplace English in terms of Speaking, Listening, Reading and Writing?

3. What are the main occasions of using English in working place?

4. What are the graduates' suggestions on course reform and students' future employment?

Instruments and Participants

The questionnaire consists of 12 questions, which are designed by the author based on the review of the other relative researches. The questionnaire can be roughly divided into 3 parts. The first part aims to get information about students' job applying, including the industry they are engaged in, their position and the nature of the company they work in. The second part is to know their English using, the using frequency, the occasions and the ability needs to be strengthened. The third part is an open question about suggestions on the curriculum reform.

The participants of this investigation are graduates majored in economics and business from School of Economics and School of Business. The number of economics graduates is 210 people, while the number of business graduates is 325 people. The male and female ratio is: 3:5. Both of the graduates from these two departments had passed College English Test Band 4. The English courses they take are alike, but they have differences in job position and working field.

\section{Procedures}

This survey was implemented in Beijing Wuzi University in 2015. The Secretary in school of Business and schools of Economics helped to hand out the questionnaire. The number of valid questionnaires from economics department is 203 out of 210 people. While the number of valid questionnaires from business department is 320 out of 325 people. Except for blank questionnaires, finally, 523 valid questionnaires are eventually received.

The data is analyzed by using excel to count the proportion of answers to each question.

\section{Data Analysis and Discussions}

\section{Their Working places and Job Responsibilities}

To answer the first question, we find that $69.45 \%$ of graduates majored in Economics choose to work in financial sector, which accounts for the major selection of occupation. The percentage of culture, sports and entertainment sector and education sector is $5.41 \%$ and $6.89 \%$ respectively, which rank at the second and third position. $36.94 \%$ tend to work in private enterprise, while $28.07 \%$ work in state-owned enterprise. It can be seen that the percentage of foreign-funded enterprise is $8.37 \%$, which receives fewer economic graduates. When asked about job responsibilities, It can be seen that $33 \%$ of graduates majored in economics work as clerks and $32.01 \%$ work as commercial service 
personnel. As is shown in figure 1 :

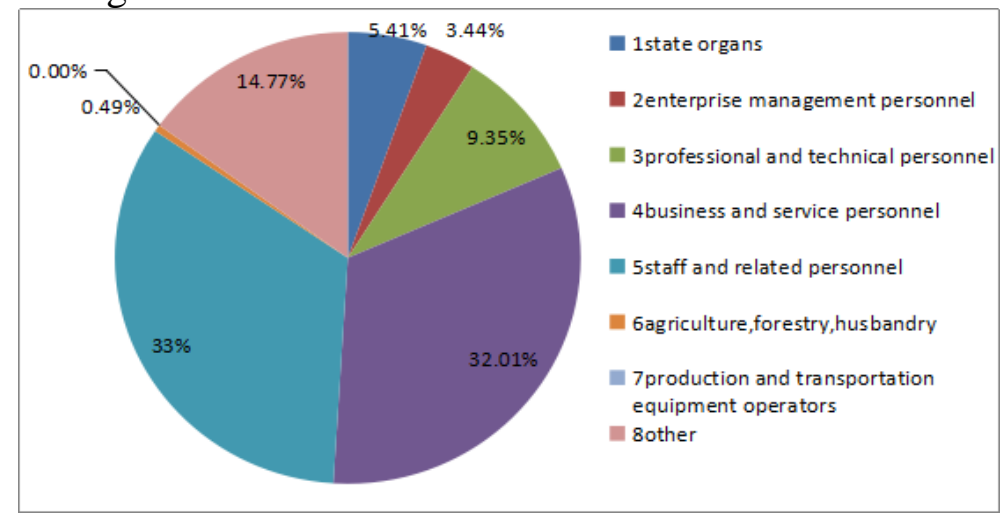

Fig.1. Job responsibilities(Economics Majors)

Business graduates tend to cover various sectors. $21.88 \%$ respond that they work in financial sector, which accounts for the largest proportion of occupation. The percentage of culture, sports and entertainment sector and education sector is $17.19 \%$ and $16.56 \%$ respectively, which rank at the second and third position. $12.24 \%$ of the participants work in rental and business service sectors. Public administration and social organization sector and Information transmission sector rank at $8.75 \%$ and $7.5 \%$. What rank next is wholesale and retail, which accounts for $6.56 \% .31 .88 \%$ of the graduates major in Business work as a clerk and related personnel, $24.06 \%$ work as commercial service personnel. These two were the major choice for career. The third and fourth position were other occupations and specialist. As is shown in figure 2:

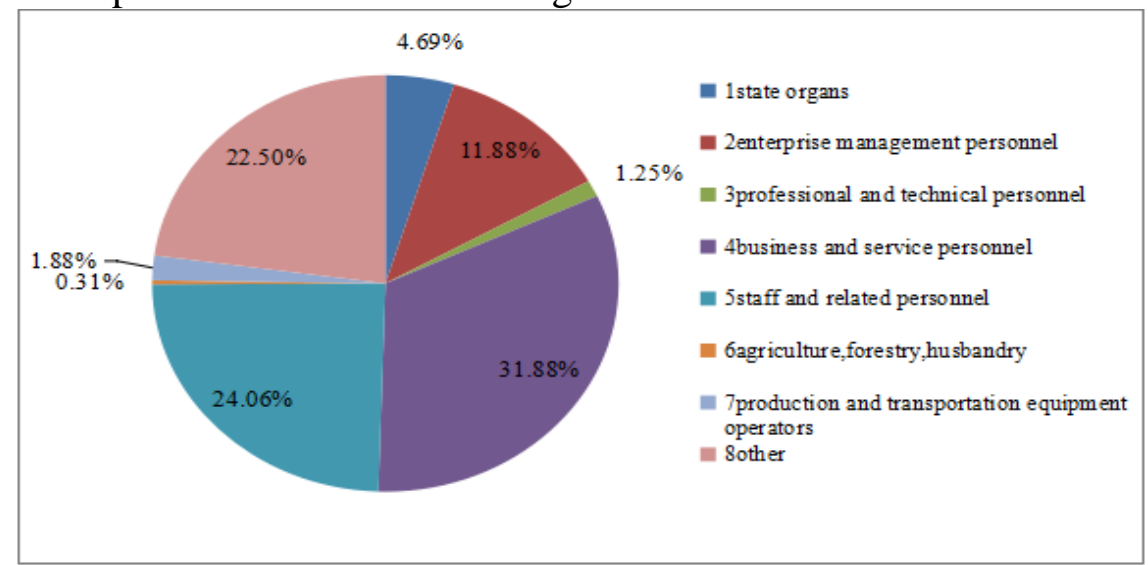

Fig.2. Job responsibilities(Business Majors)

Essential Language Skills for Workplaces

Though the majority of participants do not work in multinational companies, we find that $64.5 \%$ of the participants majored in Economics hold the view that English is important, while 6\% of them consider English useless, which constitutes a quite small proportion. The rest of graduates keep a neutral attitude. The largest proportion of respondents could be seen in the category of speaking and listening with the percentage of $75.36 \%$, while the proportion of reading and the proportion of translation were close to each other. Only $7.88 \%$ think writing is important. This result shows that the majority of graduates regard oral communication skills as important, which plays a very important role in their job. As is shown is figure 3:

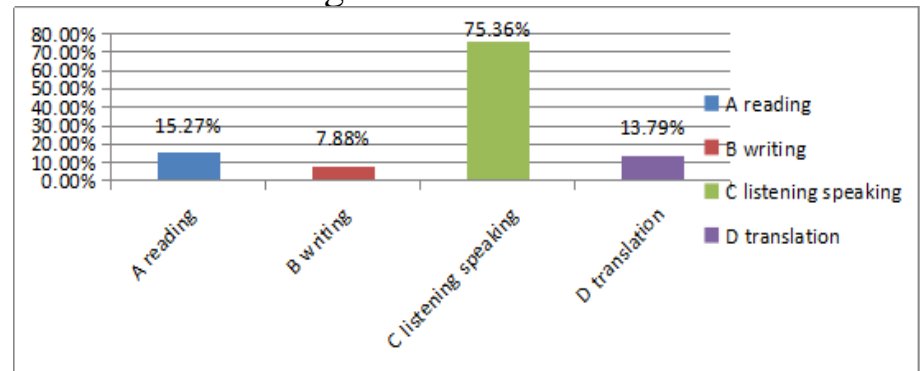

Fig.3. the essential language skill for workplaces(Economics majors) 
Similarly, over 65\% of participants majored in Business hold the view that English is important in working places. Conversely, 4\% of graduates consider English useless, which constitutes a very small proportion. The majority of the respondents could be seen in the category of speaking and listening with the percentage of $69.38 \%$, while the proportion of reading and the proportion of translation were close to each other. This result showed that graduates majored in Business hold similar view with graduates majored in Economics that oral communication skill is of great importance in workplaces, as is shown in figure 4:

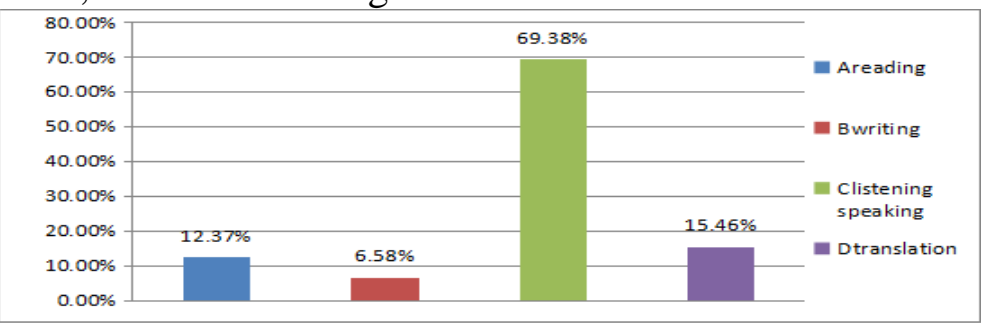

Fig.4. the essential language skill for workplaces(Business majors)

Occasions of Using English in Work places

As shown in fig.5, 47.78\% of graduates majored in Economics tend to use English to write resumes and answer interview questions. The next is to find recruitment information at the percentage of $36.45 \%$. The use for attending seminar, writing email and inquiring by phone are less frequent. The result indicates that economic graduates mainly use English in the preparatory stage of working, which include looking for job and taking part in job-interview. In their real workplaces, they use English not as much frequently as in the job-hunting period.

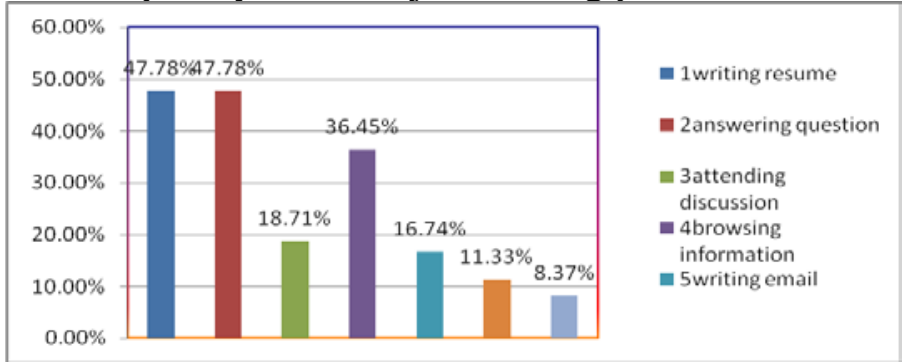

Fig.5. Occasions of Using English (Economics Majors)

As shown in the fig. 6, 57\% of the graduates majored in Business tended to use English answer interview questions, which accounts for the largest proportion of English use. Writing resume ranked in the second place. 27.5\% graduates was to find recruitment information. The needs for attending discussion, writing email and inquiring by phone was not that much needed, which accounts for $15 \%$, $18.12 \%$ and $7.18 \%$.

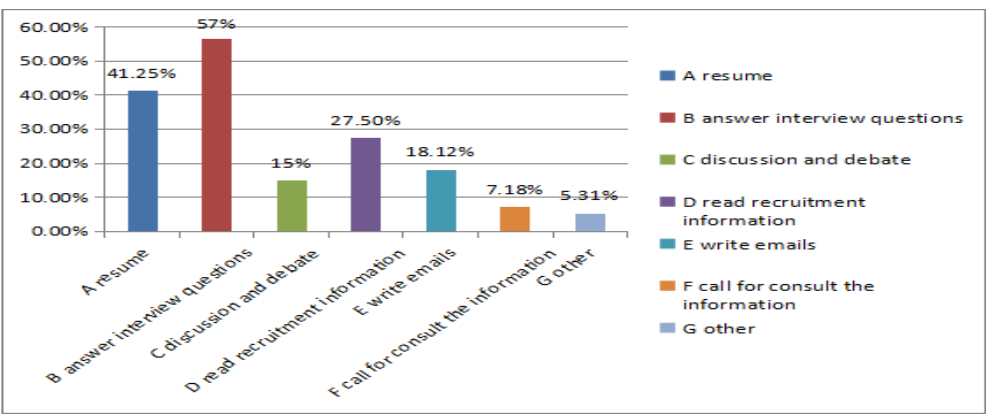

Fig.6. Occasions of Using English (Business Majors)

Graduates' Suggestions on the Course Reform

When asked about "In order to better meet the employment requirements, what is the major course that should be added", most of the graduates majored in Economics expect to have courses on professional English. At the same time, $71.42 \%$ of the participants consider courses on listening and speaking should be provided, while only $16.25 \%$ of them suggest that reading and writing courses should be added. This shows that graduates attach much importance to Oral English. Meanwhile, $18.22 \%$ of the graduates prefer cultural translation courses and only $5.41 \%$ consider exam-oriented courses as important. When the most helpful course for students' future employment 
is concerned, the largest number could be seen in the category of workplace English(61.8\%). This indicates the common requirement for students majored in economics when they were looking for job. Also, 45.32\% and 43.34\% graduates suggest that Business English and Interview English are quite helpful, which should raise teacher's attention. The percentage of Management English and Overseas English is $29.06 \%$ and $20.68 \%$ respectively, which might reflect the new trend in working field. As is shown in fig.7:

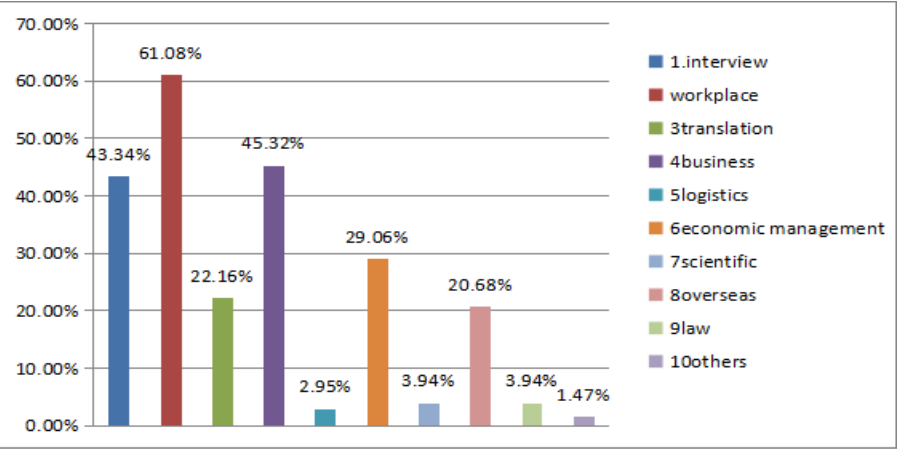

Fig.7. Helpful Courses for Future Employment (Economics Majors)

Most of the business graduates expect to add professional English courses rather than courses on translation and culture. At the same time, the proportion of participants who want to have Oral English courses is much higher than that of reading and writing courses, with the percentage of 65.62\% and 22.81\%. This shows that graduates regard oral English much more important than written English courses. Similarly, only $5.41 \%$ of the graduates majored in Business prefer to take exam guidance courses. When the most helpful course for students' future employment is concerned, the largest number could be seen in the category of workplace English(60.62\%). Also, there were 47.81\% and 44.68\% graduates who think Business English and Interview English are helpful. The percentage of Management English Overseas English is $29.06 \%$ and $20.68 \%$ respectively. These show that English in workplace and business English are still the main need in working place. As is shown in fig. 8:

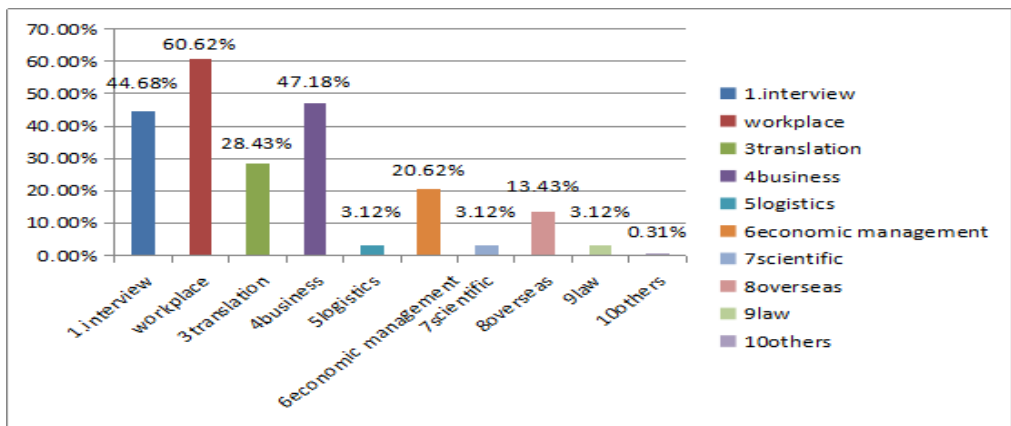

Fig.8. Helpful Courses for Future Employment (Business Majors)

\section{Conclusion}

The survey results remind us of the reforms of College English teaching and learning, which could help learners become the talents needed by the society. Here come the two suggestions on the reform.

Stimulating Students' Interest in Oral English Communication: According to the survey results, oral English is very important in hunting for a job and in the workplace. College English teaching should set aside more hours for the improvement of oral English. Improving the education of professional courses should focus on innovation abilities. Moreover, in class, teachers can simulate the real workplace oral English occasions to help students practice oral English, for an example, the telephone answering tasks, the customer visiting tasks, etc. Besides, teaching should be adjusted to accommodate students' interests. A student-oriented academic environment should be set up and various class activities be organized, such as situational dialogues, role play, topic discussion, thematic debates, storytelling. The topics of communication can include job interview, meetingclients, workplace English. In order to broaden students' interest in oral English, the 
university can organize a variety of English activities, such as establishing English corner, English speaking contest and watching English original movies, which can increase students interest in oral English communication.

Providing Courses on English for Professional Needs: Another suggestion based on the research results is to provide some courses to satisfy students' needs in future job. This means the curriculum system should be modified. Though the basic English skills should be still emphasized, teachers should put more knowledge of economics. In other words, academic listening, academic reading, academic speaking and academic writing should be introduced. According to different levels and different majors of students, the university can establish different courses. Apart from the core English courses, the university can increase courses related to cultures and technology, Business English, Logistic English and so on, which will surely be useful in the students' future career.

\section{References}

[1] B. Huang, An investigation and analysis on the science majors' motivation and strategy of learning English, Journal of Social Scientist[J], 1987(2):82-86.

[2] X. X. Liu, \& M. Hao, Analysis of Implementing Test of Oral English for Graduates in Taiyuan University of Technology, Journal of Taiyuan University of Technology[J],2004( 2): 6-20.

[3] H. Y. Liu, \& C. F. Chen. "A Study of the Use of English Among Vocational University Graduates: Centering on the Students of English ", Journal of Suzhou College of Education[J],2012 ( 2) : 4-6.

[4] R, Richterich, A Model for the Definition of Language Needs of Adults Learning a Modern Language [M], Strasburg: Council of Europe, 1972.

[5] W. H. Yu, The Function of Need Analysis in Foreign Language teaching” , Journal of Foreign Language and Foreign Language Teaching[J],2002 (3):2-11.

[6] R, Berwick, "Needs Analysis and Curriculum development in EAP: an Example of a Critical Approach.”, TESOL Quarterly[J],1989 50(4):723-738.

[7] Y. Long, A Need Analysis of College Graduates' Use of English, Journal of Higher Education[J], 2015(1):2-5. 